\title{
Neural is fundamental: Neural stemness as the ground state of cell tumorigenicity and differentiation potential
}

\section{Ying Cao}

MOE Key Laboratory of Model Animals for Disease Study and Model Animal Research Center of the Medical School, Nanjing University, Nanjing 210061, China; Email: caoying@nju.edu.cn. ORCID iD: 0000-0001-8286-9591

\begin{abstract}
Tumorigenesis is a complex biological phenomenon that includes extensive genetic and phenotypic heterogeneities and complicated regulatory mechanisms. In the recent few years, our studies demonstrate that tumor-initiating cells are similar to neural stem/progenitor cells in regulatory networks, tumorigenicity and pluripotent differentiation potential. In the review, I will make further discussion on these observations and propose a rule of cell biology by integrating these findings with evidence from developmental biology, tumor biology and evolution, which suggests that neural stemness underlies two coupled cell properties, tumorigenicity and pluripotent differentiation potential. Tumorigenicity and phenotypic heterogeneity in tumor is a result of acquirement of neural stemness in cells. The neural stemness property of tumor-initiating cells can hopefully integrate different concepts/hypotheses underlying tumorigenesis. Neural stem cells/neural progenitors and tumor-initiating cells share regulatory networks; both exhibit neural stemness, tumorigenicity and differentiation potential; both are dependent on expression or activation of ancestral genes (the atavistic effect); both rely primarily on aerobic glycolytic metabolism; both can differentiate into various cells or tissues that are derived from three germ layers, resembling severely disorganized or more severely degenerated process of embryonic development; both are enriched in long genes with more splice variants that provide more plastic scaffolds for cell differentiation, etc. The property of neural stemness might be a key point to understand tumorigenesis and pluripotent differentiation potential, and possibly explain certain pathological observations in tumors that have been inexplicable. Therefore, behind the complexity of tumorigenesis might be a general rule of cell biology, i.e., neural stemness represents the ground state of cell tumorigenicity and pluripotent differentiation potential.
\end{abstract}

Key words: neural stemness, neural stem/progenitor cell, tumor-initiating cell, neural ground state, neural default model, differentiation potential, tumorigenicity, tumorigenesis, evo-devo 


\section{Introduction}

Cancer has been the most frustrating disease not only for clinicians but also for researchers since its earliest description in an ancient Egyptian textbook about 5,000 years ago (Hajdu, 2011). The difficulty resides in the extreme complexity of cancer, as reflected by enormous inter- and intra-tumor heterogeneity, including genetic heterogeneity in most tumors caused by genetic changes and phenotypic heterogeneity in a tumor. Heterogeneity can also be the consequences of epigenetic and microenvironment changes (Burrell et al., 2013; Meacham and Morrison, 2013; Friedmann-Morvinski and Verma, 2014; Prasetyanti and Medema, 2017; Dagogo-Jack and Shaw, 2018). There have been many hypotheses and concepts trying explaining the phenomenon of cancer initiation and progression (Paduch, 2015; Hanselmann and Welter, 2016). They can explain tumorigenesis in some cases, but meet serious challenges in others (Hanselmann and Welter, 2016). These concepts have difficulties to compromise most if not all phenomena that have been observed for tumorigenesis. Moreover, these concepts or hypotheses are generally difficult to be translated into clinical applications. In this review, I will discuss our recent findings, in combination with other studies and clinical evidence, about a general rule of tumorigenesis. This grave biological phenomenon might have been suggesting a general principle of cell biology, which means that evolutionarily pre-determined state of neural stemness is the ground state for cell tumorigenicity and pluripotent differentiation potential.

\section{The 'neural default model' of embryonic pluripotent cells}

The link between neural stemness, cell tumorigenicity and pluripotent differentiation potential can be traced to the 'neural default model' of embryonic pluripotent cells in developmental biology. At the beginning of embryogenesis, a fertilized egg cleaves to generate blastomeres that further differentiate into three primary germ layers, ectoderm, endoderm and mesoderm. Ectoderm is the germ layer giving rise to both epidermis and nervous system, and other tissues/organs are derived from either endoderm or mesoderm. How the neural tissue in an early embryo is induced to form had been a major topic of research in developmental biology. The pioneering work in 1924 was that the dorsal blastopore lip, or the Spemann-Mangold organizer, of an early newt gastrula embryo was able to induce neural plate, the precursor tissue for central nervous system, in ectoderm, while the dorsal lip itself developed into mesodermal notochord (Gilbert and Barresi, 2016). However, the nature of the neural inducing activity in the organizer had not been understood for six decades until the emergence of some critical initial findings at the end of 1980s. Isolated blastula ectoderm differentiates into epidermis when cultured in neutral saline in vitro. Surprisingly, these ectodermal cells differentiate exclusively into neural tissues instead when they are disaggregated first for a few 
hours and then re-aggregated again in culture (Grunz and Tacke, 1989; Godsave and Slack, 1989; Sato and Sargent, 1989). This means that absence, but not presence, of an extracellular signal is prerequisite for neural fate decision, and neural fate might be the default fate of ectoderm. Subsequent mechanistic studies elucidated that the organizer is a wealth of secreted factors antagonizing BMP4, a TGFbeta ligand that transduces epidermis-inducing and anti-neural signaling in ectoderm (Harland, 2000; De Robertis and Kuroda, 2004; De Robertis, 2006; Gilbert and Barresi, 2016). Contrary to the initial aim of search for neural inducers, these studies reveal a non-obvious principle that neural fate is achieved by default and epidermal fate is induced during ectodermal cell fate decision, i.e., the 'neural default model' of ectoderm (Muñoz-Sanjuán and Brivanlou, 2002; Gilbert and Barresi, 2016). Besides neural and epidermal differentiation, blastula ectoderm can also be induced into mesodermal and endodermal tissues in response to inducers, such as Activin. The pluripotent differentiation potential of blastula ectodermal cells resembles that of mammalian embryonic stem cells (ESCs). The neural default fate is also manifested by ESCs. When ESCs are cultured in defined serum-free medium instead of regular medium that contains high concentration of fetal bovine serum, the cells adopt a neural fate and turn into primitive neural stem cells (primNSCs) (Tropepe et al., 2001; Ying et al., 2003a; Smukler et al., 2006). BMP4 signaling inhibits neural differentiation in amphibian ectodermal cells, which adopt a neural fate in the absence of BMP4. Likewise, it is required for maintenance of ESC pluripotency because ESCs without BMP signaling will also adopt a neural fate (Ying et al., 2003b; Malaguti et al., 2013). The neural default state of embryonic pluripotent cells provides the mechanism for cell fate decision between neural and non-neural cells at the beginning stage of differentiation during embryogenesis. If considering that embryonic pluripotent cells can be induced to differentiate into various types of non-neural somatic cells by different lineage or cell type specific factors, it can be deduced that the neural default state can be extended to somatic cells. Taken together with the tumorigenic property of embryonic pluripotent cells (Ben-David and Benvenisty, 2011), our studies and studies from other groups provide the evidence that neural state represents the ground state of cell differentiation and tumorigenicity.

\section{The link between neural stemness and cancer cells}

Downregulation/silencing of pro-differentiation genes or/and tissue-specific genes is a common feature of tumorigenesis, leading to a dedifferentiation effect and gain of stemness in cancer cells. It is expected that re-differentiation will cause a reduction or loss in cancer cell malignancy. In an attempt to drive terminal differentiation of cancer cells, we found that blocking epigenetic modification factors, HDAC1/3, EZH2, LSD1 and DNMT1, could lead to postmitotic neuron-like differentiation in cell lines of different cancers, accompanied with 
dramatic reduction in malignant features and tumorigenicity in these cells (Zhang et al., 2017; Lei et al., 2019). These epigenetic factors play extensively promoting roles and expression of their genes is upregulated or activated during initiation and progression of different cancers. Neuronal differentiation is the key property of neural stem/progenitor cells (NSCs/NPCs). The neuronal phenotype suggests that the cell lines of different cancers may have the property of NSCs/NPCs. In compatible with the property of neural stemness is the specific expression of genes of these proteins in embryonic neural cells. Comprehensive analyses on more than 3,000 cancer related genes demonstrated that most genes promoting tumorigenesis and/or being upregulated/activated during tumorigenesis are enriched in embryonic neural tissues. In contrast, genes repressing tumorigenesis and/or being downregulated/silenced during tumorigenesis are generally not expressed in embryonic neural cells (Zhang et al, 2017). This means that cancer cells and embryonic neural cells share numerous regulatory signals, which confer the property of NSCs/NPCs to cancer cells. The genes that regulate different malignant features, like mobility, proliferation, chemoresistance, stemness, dysregulated epigenetics and metabolism, etc., are all corresponding with neural specific or neural enriched genes. Therefore, I proposed that tumorigenesis might represent a process of gradual loss of original cell identity and gain of the property of NSCs/NPCs (Cao, 2017). Regulation of tumorigenesis includes thousands of cancer related genes and numerous intertwined signaling pathways. In fact, nearly all aspects of biological research have been reported to be involved in tumorigenesis. This makes tumorigenesis an incomprehensible biological phenomenon if no links between different regulatory signals are established. Due to that tumorigenesis is characterized by upregulation/activation of cancer-promoting genes, which are enriched in embryonic neural cells or neural stem cells, and downregulation of tissue-specific genes, the complexity of tumorigenesis might be reduced as a process of gain of the property of a particular cell type, the neural stemness.

There are quite some scattered pieces of evidence in clinical and basic studies showing the association between tumorigenesis and neural cells, as reviewed in Cao (2017). It was reported that NPCs promote cancer (Mauffrey et al., 2019). A recent paper shows a piece of more direct evidence that loss of a transcriptional repressor causes transition of intestinal stem cells in Drosophila into NSC-like state and drives neuroendocrine tumor formation (Li et al., 2020). Although cancer cells and NSCs/NPCs have similar neuronal differentiation potential (i.e., neural stemness), and share numerous regulatory signals, the key question is how neural stemness is related with cell tumorigenicity.

\section{Neural stemness as the source of cell tumorigenicity}

Among embryonic and adult cell types, ESCs and their artificial equivalent, the induced 
pluripotent stem cells (iPSCs), have tumorigenic potential (Ben-David and Benvenisty, 2011). When transplanted into immunodeficient mice, these cells form teratomas that contain tissue types derived from all three germ layers. Teratoma formation is also a standard assay for investigating pluripotent differentiation potential of ESCs or iPSCs. NSCs/NPCs are considered as a type of somatic stem cells, which have been thought as non-tumorigenic. However, occasional studies revealed the opposite evidence. PrimNSCs derived from ESCs or iPSCs show tumorigenicity in immunodeficient mice (Germain et al., 2012; Deng et al., 2018). The derived primNSCs were even purified to exclude the tumorigenic effect of some remaining cells that did not change fully into primNSCs (Germain et al., 2012). The mechanisms for this effect are unknown, but the most convenient explanation is due to the leftover of incompletely differentiated ESCs or the expression of MYC oncoprotein in iPSCs. Another report complicates this assumption, because tumor formation derived from transplanted human fetal NSCs in a patient was observed in a clinical practice (Amariglio et al., 2009). If we consider the neural default state and tumorigenicity of ESCs, tumorigenicity of NSCs is not irrational. As a matter of fact, tumorigenicity is an intrinsic property of NSCs/NPCs (Xu et al., 2020). First, tumorigenicity was demonstrated for primNSCs that were derived from ESCs. This should not be due to the remnant of incompletely differentiated ESCs because the former show stronger tumorigenicity than the latter. Actually, TGFbeta signaling is required for inhibition of neural differentiation and promotes non-neural differentiation of ESCs (Tropepe et al., 2001; Ying et al., 2003b; Mullen and Wrana, 2017). It suppresses tumor formation while promotes metastasis, immune regulation, etc., of cancer cells (Massagué, 2008; Seoane and Gomis, 2017). It is rather logical that tumorigenic cells are stronger in tumorigenicity in the absence of TGFbeta signaling. PrimNSC-derived tumors are composed of tissues of all germ layers, including immature neuroectodermal cells, differentiated neuronal cells, or keratinized structures from ectoderm, and full spectrum of tissues from mesoderm and endoderm (Xu et al., 2020). These tumors are very similar to teratoma formed by ESCs, suggesting that primNSCs, representing initial neuroectodermal cells, are pluripotent in differentiation potential. Second, tumorigenicity was demonstrated for a NSC cell line derived from E9 mouse embryos (Xu et al., 2020). Subcutaneous transplantation of the cells caused formation of tumors, and tail vein injection of the cells led to formation of tumors in various tissues or regions of mouse body. The tumors contain also different tissues of three germ layers, but with less abundance of tissue types than in primNSC-tumors. Third, tumorigenicity was demonstrated for NPCs that were isolated from cortices of E13.5 embryos. Different tissue types of neural and non-neural lineages can also be observed in these tumors. Moreover, NSCs/NPCs contribute to chimera formation in chick and mouse embryos (Clarke et al., 2000; Tropepe et al., 2001). These analyses suggest that NSCs/NPCs have both tumorigenic and pluripotent differentiation potential. 
Many types of adult tissue stem/progenitor cells have been identified. However, there seem to be no evidence for that other tissue stem/progenitor cells have tumorigenic potential. Mesenchymal stem cells (MSCs) have been extensively investigated for their roles during tumorigenesis. They exhibit seemingly both a promoting and an inhibitory effect on tumor progression (Serakinci et al., 2018). However, the cells themselves exhibit no tumorigenicity (Ra et al., 2011; Sykova and Forostyak, 2013; Yong et al., 2018; Xu et al., 2020). Hematopoietic stem cell transplantation has been widely used as a treatment for hematological cancers and other diseases. In our study, we also observed that embryonic fibroblasts and myoblasts are not tumorigenic (Xu et al., 2020). When either the muscle differentiation factor Myod1 was lost in myoblasts or a transcriptional repressor was lost in intestinal stem cells, the resulting cells gained neural stemness and tumorigenicity (Li et al., 2020; Xu et al., 2020). In contrast, decrease in neural stemness via differentiation into neuronor muscle-like cells, tumorigenicity is reduced or lost (Zhang et al, 2017; Xu et al., 2020). These lines of evidence from both NSCs/NPCs and genetically manipulated somatic cells indicate that the property of neural stemness is the source of tumorigenicity.

Both cancer cells and NSCs/NPCs have the neuronal differentiation potential and share similar regulatory networks. Do cancer cells behave like NSCs/NPCs in other aspects? NSCs/NPCs are characteristic of free-floating neurosphere formation in defined NSC serum-free medium. Cancer cells capable of tumor formation (or tumor initiating cells, TICs) can form spherical structures in a same culture condition. These structures express neural stemness markers, resembling neurospheres of NSCs/NPCs (Xu et al., 2020). The ability in neurosphere formation is a reflection of neural stemness and tumorigenicity of cancer cells. Cells without neurosphere formation could mean that they have very weak tumorigenicity, or they are not sufficient to initiate tumor. Weak tumorigenicity could be detected using more sensitive approaches. For example, the osteosarcoma cell U-2OS does not form neurospheres and displays no tumorigenicity in nude mice. However, it is very weakly tumorigenic in the most severely immunodeficient NOD/SCID IL2R-gamma-0 (NSG) mouse (Lauvrak et al. 2013). Non-cancer cells, such as MEFs, myoblasts and MSCs, do not form neurospheres and are not tumorigenic. Tissue stem cells also form spherical structures in serum-free culture, though, the media are different in composition. Specific growth factors or even a specific culture condition is required for a particular type of tissue stem cells. For example, MSCs form spheres in an appropriate serum-free medium (Méndez-Ferrer et al., 2010), but do not in the serum-free medium for neurosphere formation (Xu et al., 2020). More importantly, xenograft tumors formed by transplanted NSCs/NPCs or cancer cells show differentiation of tissues or cell types from different lineages, but not the differentiation hierarchy of a type of tissue stem cells along a particular lineage. Neurosphere formation is an indication of neural 
stemness and tumorigenicity. In line with the experimental observation of pluripotent differentiation potential of NSCs/NPCs (Clarke et al., 2000; Tropepe et al., 2001; Xu et al., 2020), bioinformatic analysis also revealed that neural genes are most closely associated with neural development, embryonic development and cancer, whereas non-neural genes are not (Xu et al., 2020).

The link between neural stemness and cell tumorigenicity has been implied by many lineage-tracing studies. For instances, CD133 (or PROM1) identifies human colon cancer-initiating cells (Ricci-Vitiani et al., 2007); Msi1-expressing cells are identified as key drivers of pancreatic cancer (Fox et al., 2016); Sox2-expressing cells are identified as tumor-propagating cells and show cancer stem cell (CSC) property in squamous-cell carcinoma (Boumahdi et al., 2014); Dclk1 labels intestinal tumor stem cells, which produce tumor progeny (Nakanishi et al., 2013). In these studies, CD133, Sox2, Msi1 or Dclk1, which are frequently used as CSC markers, are either typical markers for neural stem cell and/or their genes are specifically expressed in neural tissues in vertebrate embryos (Fig. 1). Their use as markers of NSCs/NPCs has been extensively documented. These studies demonstrate that the markers label NSCs/NPCs label TICs, suggesting an association between TICs and neural stemness. It is usually argued that neural stemness markers are sometimes also markers for other types of stem/progenitor cells. This issue will be discussed later.

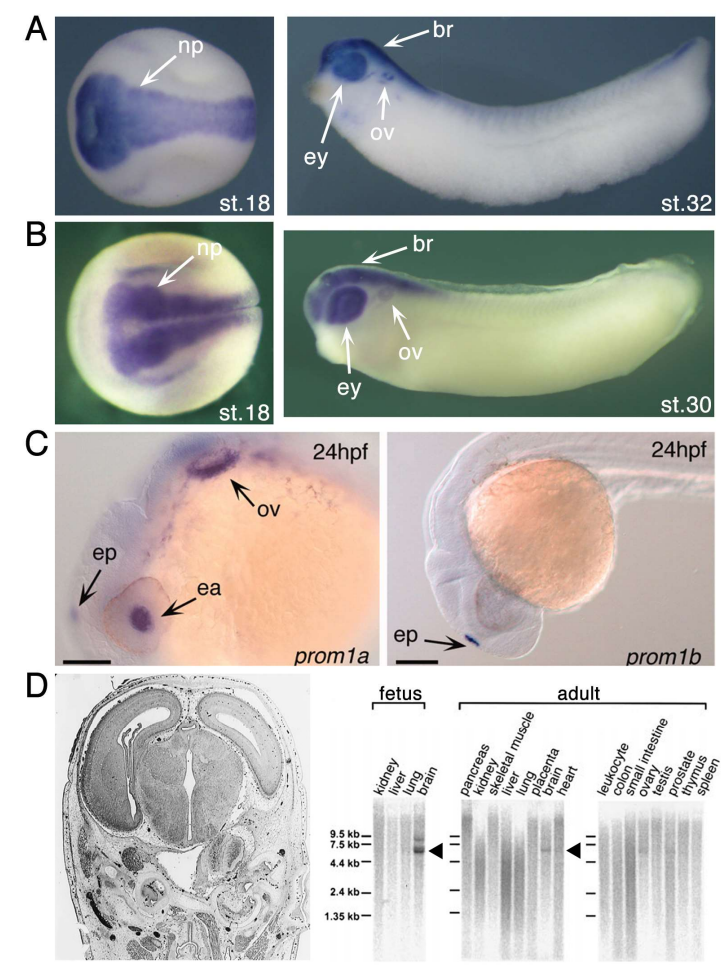

(Adapted from Matsumoto et al., 1999).
Fig. 1. Neural specific or enriched expression of the genes for cancer stem cell markers during vertebrate embryonic development or in adult. (A, B) sox2 (A) and msil (B) expression pattern during Xenopus embryogenesis, as detected with whole mount in situ hybridization. st. 18 , st.30 or st.32 refer to the Nieuwkoop and Faber developmental stages of Xenopus laevis. The anterior of the embryos is to the left. np: neural plate; br: brain; ey: eye; ov: otic vesicle. (Adapted from Zhang et al., 2017). (C) $c d 133$ (promla and prom $1 b$ in zebrafish) expression pattern during zebrafish embryogenesis, as detected with whole mount in situ hybridization. Developmental stage is indicated ( 24 hours post fertilization (hpf)). The anterior of the embryos is to the left. ea: eye anlage; ep: epiphysis; ov: otic vesicle. (Adapted from McGrail et al., 2010). (D) Left: Localization of Dclk1 (also called KIAA0369) to the central nervous system of an E17 rat fetus, as detected by immunohistochemistry. (Adapted from Mizuguchi et al., 1999). Right: Specific expression of DCLK1 in the brain of human fetus and adult (indicated with a solid triangle), as detected by Northern blotting. 


\section{Tumor phenotypic heterogeneity}

A tumor is composed of heterogeneous populations of cells. How the heterogeneity is generated is also a complex issue (Marusyk et al., 2012; Burrell et al., 2013; Meacham and Morrison, 2013; McGranahan and Swanton, 2015; Quintanal-Villalonga et al., 2020). In general, two major models have been proposed. One is the clonal evolution model, in which heterogeneity is explained as a result of natural selection. This model emphasizes the central role of genetic heterogeneity arising from a Darwinian-like evolution in phenotypic heterogeneity. It is challenged by the cancer stem cell (CSC) model, in which a subpopulation of cancer cells has the ability of indefinite self-renewal, initiating tumor formation and driving tumor growth. In this model, heterogeneity is generated by differentiation of CSCs (Clevers, 2011; Marusyk et al., 2012; Beck and Blanpain, 2013; Prasetyanti and Medema, 2017), comparable to the tissue hierarchy generated by normal stem cells. However, it has not been characterized whether CSCs in different cancers exhibit the stemness of a similar type of stem cells, or CSCs in each cancer exhibit the stemness of the stem cells of the respective tissue of tumor origin, or CSCs are of a mysterious character and not comparable with any known stem/progenitor cell types. CSCs are also termed as tumor-initiating cells (TICs), and generally identified with certain markers. However, CSCs identified with markers might represent just a subpopulation of TICs, since CSCs are also heterogeneous cell populations. For an instance, CD133 is one of the most frequently used CSC markers. Both CD133+ and CD133- metastatic cancer cells initiate tumors in colon cancer (Shmelkov et al., 2008), and CD133-positive cells and CD133-negative cells from primary glioblastoma seem to be equally tumorigenic (Beier et al., 2007). Hence, TICs might be a more generalized expression for the cells capable of tumor initiation, regardless of the presence or absence of particular CSC markers. TICs form tumors in nude mice. Nevertheless, how tissues or cells are differentiated in xenograft tumors had not been examined carefully except teratomas formed by transplanted ESCs, iPS or teratocarcinoma cells. In our study, we observed that xenograft tumors formed by cancer cells contain tissue or cell types derived from three germ layers, as revealed by tissue-specific gene expression assay and immunohistochemistry assay with specific markers (Xu et al., 2020). Tissue or cell differentiation from different lineages in xenograft tumors formed by TICs is rather similar to the xenograft tumors formed by NSCs/NPCs. Tumors of primNSCs are characteristic of teratoma/teratocarcinoma because they contain well differentiated tissues with readily identifiable morphology. Tumors from E9 NSCs and E13.5 NSCs/NPCs are less abundant in tissue diversity. Nevertheless, expression of markers for ectodermal, endodermal and mesodermal lineages was all detected. Similarly, xenograft tumors from cells of different cancers, for example, melanoma, colorectal carcinoma or glioblastoma, show significant expression of lineage markers or contain cells 
from different lineages, including SOX1-positive cells and MAP2-postive cells derived from ectoderm, ACTA2- and BGLAP-positive cells derived from mesoderm, AFP-positive cells derived from endoderm. These cell types were also present in tumors derived from Myod1 knockout myoblast cells (Xu et al., 2020), meaning that blocking of a pro-differentiation factor leads to loss of myoblast identity, gain of neural stemness and cell tumorigenicity, and re-acquirement of differentiation potential. Besides these findings, pluripotent differentiation potential of particular type of cancer cells, the teratocarcinoma cells and their capability of contribution to formation of chimera embryos have been observed in nearly a half century ago (Mintz and Illmensee, 1975; Papaioannou et al., 1975). Although CSCs have been described and delicate molecular mechanisms for establishing CSC phenotypes have been proposed in numerous publications, the nature of CSCs has not been characterized. Consequently, it is not known whether CSCs could differentiate along the differentiation lineage of a tissue stem/progenitor cell or the lineages of other types of stem/progenitor cells. In fact, in vitro generated cells with CSC properties have the potential to differentiate into cells expressing markers for neuron, endothelial cells and muscle (Scaffidi and Misteli, 2011). CSCs in glioblastoma can differentiate into tumor-endothelium or vascular pericytes (Ricci-Vitiani, 2010; Wang et al., 2010; Cheng et al., 2013). Colon cancer stem cells reveal a multi-lineage differentiation capacity (Vermeulen et al., 2008). These cells do not follow the differentiation hierarchy of a particular type of tissue stem cells along a fixed lineage. In summary, cancer cells capable of tumor initiation, or TICs, exhibit property of neural stemness and have the potential of differentiation into diverse tissue or cell types, contributing to intra-tumor phenotypic heterogeneity.

The phenotypic difference between tumors has been a primary focus of tumor research. In fact, there exist many cell or tissue types in common among different types of tumors. In each tumor, there are immature neuroepithelial-like cells that function as TICs and express neural stemness markers, such as SOX1-positive cells. Indeed, NSCs can be derived, at least, from human teratomas (Kim et al., 2019). Tumors also contain neuron-like cells or nerves (Venkataramani et al., 2019; Venkatesh et al., 2019; Zeng et al., 2019; Reavis et al., 2020). Cells expressing smooth muscle protein ACTA2 are widely detected in different tumors. AFP has been used as a marker for cancers of the liver, testicles, and ovaries, and is expressed also in other types of cancers, such as colorectal and gastric cancers (Yachida et al., 2003; Anzai et al., 2015; Gong et al., 2018). Moreover, pathological studies reveal similar tissues or cells in different tumors. For example, osteoclasts are multinucleated giant cells that are responsible for bone dissolution and absorption. They are not present in normal tissues other than bones. Nevertheless, similar cells have been found in tumors of pancreas (Abid and Gnanajothy, 2019; Njoumi et al., 2014; Sah et al., 2015; Togawa et al., 2010; Bauditz et al., 
2006), liver (Bauditz et al., 2006; Dioscoridi et al., 2015; Ikeda et al., 2003; Kuwano et al., 1984; Rosai, 1990), skin (Goel et al., 2011; Al-Brahim and Salama, 2005; Jiménez-Heffernan et al., 2018; Houang et al., 2015), lung (Nakahashi et al., 1987; Matsukuma et al., 2014; Lindholm et al., 2019; Kong et al., 2015; Dahm, 2017), breast (Stewart and Mutch, 1991; Agnantis and Rosen, 1979; Fadare and Gill, 2009; Ginter et al., 2015; Ohashi et al., 2018), and in many other tumors. Osteoid and bone formation was found in different cancers, such as breast cancer and melanoma (Hoorweg et al., 1997; Dekkers et al., 2019), etc. Thus, under the appearance of big phenotypic difference between tumors, there are in fact many tissue or cell types in common.

The intra- or inter-tumoral heterogeneity should be a result of differentiation potential of TICs, under the control of intra- and extracellular signals. Differentiation potential of TICs should also account for cancer types that appear irrelevant with the tissue of origin, e.g. primary osteosarcoma of the breast (Dekkers et al, 2019) and the 'muscle cancer' (rhabdomyosarcoma) from non-muscle cells (Drummond et al., 2018), for which the mechanisms are unknown. Teratomas/teratocarcinomas are considered as a special type of tumor since their initiation and progression is similar to a chaotic process of embryonic development, which appears rather different from other types of tumors. Nevertheless, the pluripotent differentiation potential of NSCs and TICs suggests an intrinsic link between teratomas/teratocarcinomas and other types of tumors. TICs of teratomas/teratocarcinomas should be more similar to primNSCs in differentiation potential, producing a tumor of a disorganized mixture of well-differentiated tissues or organs. The differentiation potential of TICs of other types of tumors might be more defected due to extensive genetic, epigenetic and microenvironmental variations, in particular the defect in pro-differentiation or tissue-specific genes, leading to tumors of more severely defected cell or tissue differentiation. These tumors can be considered as degenerated or more severely defected forms of teratomas/teratocarcinomas.

\section{Neural state as the ground state for tumorigenicity and pluripotent differentiation potential}

The earliest demonstration of the link between cell tumorigenicity and pluripotent differentiation potential was conducted on embryonic carcinoma cells (ECs) derived from teratocarcinoma. After the finding of ECs in more than a decade later, mouse ESCs were isolated and the properties of ESCs were observed to be very comparable with those of ECs. Both cell types form teratomas and display pluripotent differentiation potential (Solter, 2006). From historical view, it was a type of cancer cells, the ECs, that inspired the study of pluripotent property of ESCs. It was postulated that tumorigenicity and pluripotency are two 
coupled cell properties (Knoepfler, 2009; Riggs et al., 2013). Characterization of iPS was also dependent on the two cell properties, which is usually performed with xenograft tumor formation assays in nude mice. Nevertheless, why should pluripotent cells be tumorigenic has been largely unknown. Our recent study and studies by others suggest that the neural ground state is the link between cell tumorigenicity and pluripotent differentiation potential.

The default fate of embryonic pluripotent cells is neural. Blocking endogenous factors in somatic cells also leads to the gain of a neural property at the cost of original cell identity (Cheng et al., 2014; Li et al., 2020; Xu et al., 2020). This means that either embryonic pluripotent cells or somatic cells turn into neural cells when appropriate endogenous factors are blocked. The effect reflects that neural state might be the ground state of cells, upon which all cells are formed. The question is, why the property of neural stemness, but not of other cell types, is the ground state of tumorigenicity and differentiation? The answer resides in evolution. Among the three germ layers, origin of ectoderm is the earliest during evolution, followed sequentially by endoderm and mesoderm (Domazet-Lošo et al., 2007). Analysis of neural genes and non-neural genes in the ectoderm showed that one peak of emergence of neural genes is already present in the time point representing the last common ancestors (LCA) of eukaryotes and the other is at the time of emergence of the eumetazoa (Domazet-Lošo et al., 2007), indicating that genes relevant for neural development have an earlier evolutionary origin. Metazoans are all evolved from unicellular ancestors, an earlier origin suggesting that neural genes might play a critical role in multicellularity. Monosiga brevicollis, Amphimedon queenslandica and Trichoplax adhaerens are the closest species representing transition from unicellularity to multicellularity, and share a last common unicellular ancestor in more than 600 million years ago. M. brevicollis represents the closest unicellular relatives of metazoans (Sebé-Pedrós et al., 2017). A. queenslandica represents the oldest surviving metazoan and an evolutionary intermediary between unicellular choanoflagellate protists and eumetazoans, and T. adhaerens is the basal eumetazoan species. Interestingly, a majority of genes with enriched expression in vertebrate embryonic neural tissues can be traced back to these species (Xu et al., 2020), suggesting that the founders of most neural genes have emerged during the transition from unicellularity to multicellularity. More importantly, more than $60 \%$ of genes in M. brevicollis that are homologous to vertebrate genes are genes enriched in embryonic neural cells. The overwhelming presence of founders of vertebrate neural genes in the closest unicellular relative of metazoan implies that the last common unicellular ancestor is biased towards a neural state (Xu et al., 2020). The vertebrate homologous genes in M. brevicollis are mostly involved in organelle part, intracellular part, cytoplasm, cytosol, etc., that are basic functional constituents common to all animal cells, such as ribosomes and proteasomes. Moreover, these genes are mainly associated with regulation of cell cycle, metabolism and 
gene expression. This means that a neural biased state in the unicellular ancestors was the beginning state or ground state of multicellularity, and this state was an adaptation of unicellular ancestors to the low oxygen environment in about 600 million years ago. Coherently, the intrinsic property of adaptation of neural state to hypoxic environment is reflected by that low oxygen condition enhances the property of neural stemness and the generation of NSCs from fibroblasts (Clarke et al., 2009; Cheng et al., 2014).

The neural ground state is also reflected by that the machineries required for basic cellular physiological functions and developmental programs are mostly enriched in embryonic neural cells. Here are some examples. Expression of genes promoting cell cycle is enriched only in neural cells during embryogenesis (Fig. 2A), meaning that embryonic neural cells undergo faster cell growth and proliferation than non-neural cells. Sufficient ribosome biogenesis and increased overall protein production is critical for cell growth (Baserga, 2007; Turi et al., 2019). A faster cell cycle means a requirement for more protein synthesis. Correspondingly, expression of genes for the machinery of ribosome biogenesis and the machinery for protein translation is also enriched in embryonic neural cells (Fig. 2B, C). During normal neural development, ribosome biogenesis is downregulated with increased differentiation of NSCs in mouse embryos (Chau et al., 2018), an indication of higher requirement for ribosome biogenesis in more proliferative and fast growing cells. The machinery for protein quality control and turnover should match the situation of fast protein production to guarantee protein homeostasis for cell growth and proliferation. Coherently, genes for the components of proteasome, which is responsible for protein degradation, show neural biased expression in Xenopus or zebrafish embryos (Fig. 2D). Alternative splicing has been proposed to underlie phenotypic novelty during evolution (Bush et al., 2017). It contributes to developmental programs and plays critical roles in controlling cell differentiation, lineage determination, tissue or organ formation and homeostasis (Baralle and Giudice, 2017; Bush et al., 2017). Genes for the components of RNA splicing machinery are expressed dominantly in embryonic neural cells (Fig. 2E). This neural dominant expression is in agreement with that neural genes are enriched in long genes, which contain more exons and introns than those in non-neural genes (Xu et al., 2020) (Table 1). Higher alternative splicing activity generates more transcripts that demand more machineries like ribosomes and proteasomes. Embryonic neural enrichment can also be found for other basic machineries. Interestingly, a major part of genes for these basic machineries have a unicellular origin (Xu et al., 2020), suggesting that the embryonic neural cells represent the direct descendant cells of the unicellular ancestors. Neural enriched expression during embryogenesis has been also observed for most of genes for epigenetic modification factors, including histone lysine deacetylases $h d a c 1-3$, histone acetyltrasferase $c r e b b p$, DNA methyltransferase $d n m t 1$, lysine 
methyltransferases setdbl-dot ll, lysine demethylases $k d m l a-k d m 6 b$, arginine methyltransferases prmt1-prmt7, and the putative arginine demethylase jmjd6 (Fig. 2F). Epigenetic modification factors are involved widely in early embryonic development, maintenance of stemness and differentiation of stem cells, etc. An additional example is the neural dominant expression of the factors that reprogram somatic cells into pluripotent stem cells and of the reprogramming co-regulators that improve the efficiency of reprogramming (Xu et al., 2016) (Fig. 2G, H). Enrichment of the genes for these machineries for basic cellular physiological functions implies that all machineries should all exist in a high level and function efficiently to meet the requirement by the fast-growing, highly proliferative, and differentiation potential of embryonic neural cells or neural stem cells. The neural biased expression is in contrast to that these genes should be uniformly expressed, as usually thought. These machineries do exist in other cell types, but usually at a lower level.

Table 1. Difference in average gene length and exon/intron numbers between neural and non-neural genes

\begin{tabular}{|l|l|l|}
\hline & 5283 neural enriched genes & 7238 non-neural genes \\
\hline $\begin{array}{l}\text { Average gene length } \\
\text { (nucleotides) }\end{array}$ & 92765 & 42911 \\
\hline $\begin{array}{l}\text { Average number of } \\
\text { exons/introns per gene }\end{array}$ & $13 / 12$ & $9 / 8$ \\
\hline
\end{tabular}

Accordingly, fast cell growth and proliferation is a typical feature of cancer cells and genes promoting cell cycle are usually upregulated during and promote tumorigenesis. Similar to the situation in embryonic neural cells, cancer cells show elevated levels of ribosome biogenesis, which plays a promoting role in tumorigenesis (Bustelo and Dosil, 2018; Catez et al., 2018; Pelletier et al., 2018; Turi et al., 2019). Translation initiation factors are also usually upregulated in cancers and correlate with disease progression and poor prognosis (Bhat et al., 2015). Moreover, cancer cells also show higher levels of proteasomes and proteasome activity for protein quality control, so as to promote their survival, growth and metastasis (Chen et al., 2017; Soave et al., 2017; Rousseau and Bertolotti, 2018). Splicing factors function as both oncoproteins and tumor suppressors, depending on the functions of spliced variants they generate, but mostly being upregulated in cancers and oncoproteins (Dvinge et al., 2016; Wang and Lee, 2018). Dysregulated epigenetics is also typical feature of tumorigenesis. Epigenetic modification factors are mostly upregulated and play primarily a promoting role in cancers, which has been reviewed extensively (Bennett and Licht, 2018; Mohammad et al., 2019). Moreover, the reprogramming factors and co-regulators are also mostly cancer promoting factors, primarily contributing to the gain or maintenance of stemness in cancer cells. Therefore, similar to the situation in embryonic neural cells or neural stem cells, all these basic machineries should be coordinately upregulated, such that they can 


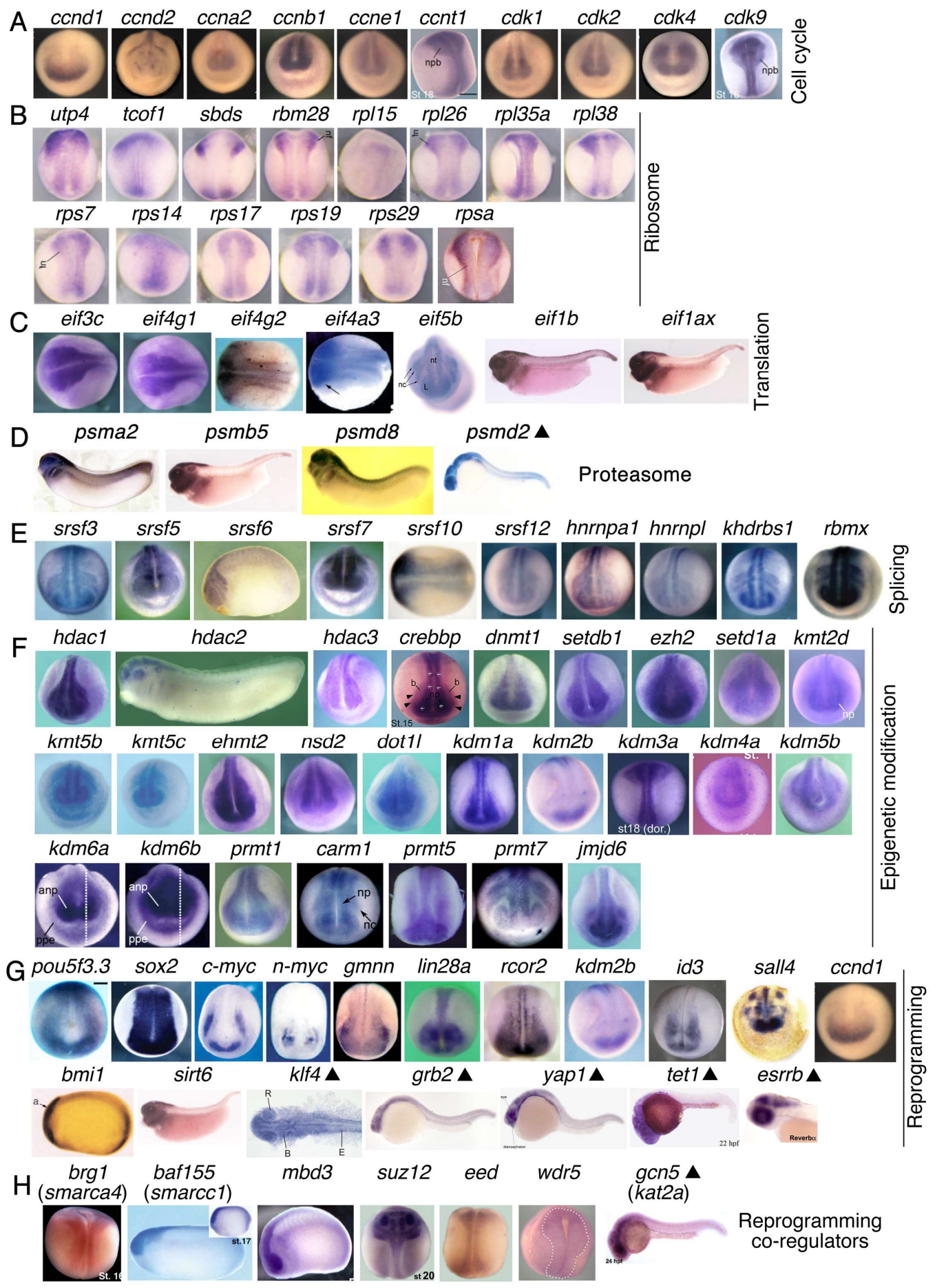

Fig. 2. Neural specific or enriched expression of the genes for basic physiological machineries or developmental programs in vertebrate embryos. (A-E) Neural specific or enriched expression of the genes for components of the machineries of cell cycle (A), ribosome biogenesis (B), protein translation (C), proteasome (D) and RNA splicing (E) in Xenopus or zebrafish (marked with a solid triangle) embryos. (F) Neural specific or enriched expression of the genes for epigenetic modification factors in Xenopus embryos. $(\mathrm{G}, \mathrm{H})$ Neural specific or enriched expression of the genes for reprogramming factors $(\mathrm{G})$ and reprogramming co-regulators $(\mathrm{H})$ in Xenopus or zebrafish (marked with a solid triangle) embryos. Xenopus embryos shown here are at neurula stages (for example, all panels in A and B) and tailbud stages (for example, panels for eiflb and eiflax in $\mathrm{C}$, and psma2, psmb5 and psmd8 in C), and zebrafish embryos are at stages between Prim-5 to Prim-22. Expression patterns of only a part of genes 
of these machineries and developmental programs are shown here as examples. Expression pattern data are from Xenopus (www.xenbase.org) and zebrafish (www.zfin.org) databases or literatures therein. A comprehensive list of genes with neural specific or enriched genes can be found in Additional file 2: Table S4 in Xu et al., 2020.

be expressed in a higher level to satisfy the higher requirements by cancer cells than by normal tissue cells. Enrichment of the basic machineries of cellular physiological functions and developmental programs in embryonic neural cells or neural stem cells consolidates that neural stemness represents a ground or basal state upon which other cell types are derived. These basic machineries should be repressed in response to differentiation, leading to a reduced level in differentiated cells. When a differentiation signal is removed/repressed in a cell, like what occurs during tumorigenesis, the cell will turn back to the ground state, a highly proliferative and fast-growing state that needs more machineries for cell cycle, protein synthesis, translation, degradation, splicing, etc.

Since neural-biased unicellular state is the beginning state of multicellularity and cell type diversification, emergence of non-neural state requires inhibition of the initial state. In other words, neural cells are formed by an evolutionarily predetermined ground state and non-neural cells are induced upon the neural ground state. Induction of non-neural cells needs repression of neural ground state by non-neural pro-differentiation signals. Accordingly, genes enriched in embryonic neural cells, such as those discussed above, are downregulated or repressed in non-neural cells, ultimately leading to the reduction of cell tumorigenicity and pluripotent differentiation potential. Besides evolutionary advantage, neural genes are characteristic of over-representation of long genes with more exons and introns, as compared with non-neural genes (Gabel et al., 2015; Zylka et al., 2015; Xu et al., 2020), with the average length of neural genes in general being about two times of the length of non-neural genes (Xu, et al., 2020) (Table 1). Longer genes facilitate binding of different regulators, generating more spliced variants or forming secondary or tertiary structures, which means that longer genes can serve as more flexible scaffolds for regulatory signals required for generation of diverse types of cells. Shorter genes should have less flexibility. In this regard, enrichment of longer genes may confer neural stemness the plasticity and make it a more appropriate initial state for cell differentiation.

During tumorigenesis, tissue-specific genes are usually downregulated or silenced in cells. This would cause de-repression of neural ground state and facilitate somatic cells to return to the ground state, the most direct route that needs no instructive signals. The resulting cells acquire the property of neural stemness, the capability of self-renewal and differentiation into cells of different lineages. An atavistic effect of tumorigenesis has been suggested because cancer is driven by ancestral gene regulatory networks, and cancer genes are mostly conserved in unicellular and basal species of multicellular organisms (Domazet-Lošo and 
Tautz, 2010; Bussey et al., 2017; Trigos et al., 2017; Trigos et al., 2018). Moreover, cancer development is suggested as a reverse evolution from multicellularity to unicellularity (Alfarouk et al., 2011; Chen et al., 2015). The metabolic style in cancer cells (or more precisely, TICs) also reflects the characteristics of metabolism of the last common ancestor of unicellular and multicellular organisms in an oxygen-deficient environment in about 600 million years ago. Like in cancer cells, NSCs and pluripotent stem cells (PSCs) rely mainly on aerobic glycolysis as well (Kim et al., 2014; Zheng et al., 2016; Intlekofer and Finley, 2019; Nishimura et al., 2019). PSC differentiation into NSCs does not change or even increases glycolysis, whereas PSC differentiation into mesoderm and endoderm or NSC differentiation into neurons decreases glycolytic flux (Zheng et al., 2016; Intlekofer and Finley, 2019). Reprogramming of somatic cells into pluripotent state causes metabolic shift from oxidative phosphorylation to glycolysis again (Nishimura et al., 2019). Cancer cells are characteristic of genomic instability and gene mutations, which are also the feature of the genomes of unicellular species under adverse environment (Yona et al., 2012; Cisneros et al., 2017). Coincidentally, both NSCs and PSCs are prone to genomic instability (Varela et al., 2012; Peterson and Loring, 2014). As mentioned above, enrichment of longer genes with more splice variants is a unique feature of neural cells, and this enrichment is also present in pathways linked to cancers (Sahakyan and Balasubramanian, 2016). These shared features, as summarized in Table 2, also suggest an intrinsic link between neural stemness, cell tumorigenicity and pluripotent differentiation potential.

Table 2. Comparison of the properties of three types of cells

\begin{tabular}{|l|l|l|}
\hline Neural stem/progenitor cells & Tumor-initiating cells & Pluripotent stem cells (PSCs) \\
\hline Tumorigenic & Tumorigenic & Tumorigenic \\
\hline $\begin{array}{l}\text { Defined by ancestral regulatory } \\
\text { networks }\end{array}$ & $\begin{array}{l}\text { Dependence on } \\
\text { activation of ancestral } \\
\text { regulatory networks }\end{array}$ & Unknown \\
\hline Neural stemness & Neural stemness & $\begin{array}{l}\text { Neural stemness as the default state } \\
\text { of PSCs }\end{array}$ \\
\hline $\begin{array}{l}\text { Pluripotent differentiation } \\
\text { potential }\end{array}$ & $\begin{array}{l}\text { Pluripotent } \\
\text { differentiation potential }\end{array}$ & Pluripotent differentiation potential \\
\hline $\begin{array}{l}\text { Characteristic of aerobic } \\
\text { nlycolysis. Differentiation into } \\
\text { neurons decreases glycolysis }\end{array}$ & $\begin{array}{l}\text { Characteristic of aerobic } \\
\text { glycolysis }\end{array}$ & $\begin{array}{l}\text { Characteristic of aerobic glycolysis. } \\
\text { Differentiation into NSCs does not } \\
\text { change or increases glycolysis; } \\
\text { differentiation into mesoderm and } \\
\text { endoderm decreases glycolysis }\end{array}$ \\
\hline $\begin{array}{l}\text { Determined by neural biased } \\
\text { state of last common unicellular } \\
\text { ancestors }\end{array}$ & $\begin{array}{l}\text { Tumorigenesis as a } \\
\text { process of reverse } \\
\text { evolution and also a } \\
\text { process of gain of neural } \\
\text { stemness }\end{array}$ & Unicellular origin of pluripotency \\
\hline $\begin{array}{l}\text { Prone to genomic instability } \\
\text { more splice variants }\end{array}$ & $\begin{array}{l}\text { Enriched in long genes } \\
\text { with more splice variants }\end{array}$ & Unknown \\
\hline
\end{tabular}




\section{General stemness versus specific stemness}

Amphibian blastula ectodermal cells and mammalian ESCs are derived from cells that appear at cleavage stage of embryogenesis, and considered as the basis for differentiation. By contrast, NSCs are considered as a type of tissue stem cells because they emerge later than pluripotent embryonic cells, are derived from ectoderm and exhibit differentiation potential for neural lineage during normal embryonic development. Therefore, change of ESCs into primNSCs is considered as a differentiation effect and loss of pluripotency. However, based on the analyses above, this change might be more logically interpreted as an effect of restoration of neural ground state of ESCs. The induced pluripotency should be per se also an effect of gain of neural stemness in somatic cells. As shown in Fig. $2 \mathrm{G}$ and $\mathrm{H}$, the four original reprogramming factors, Sox2, c-Myc, Oct4 and Klf4, and subsequent alternative reprogamming factors and reprogramming co-regulators are enriched in neural precursor/progenitor cells during vertebrate embryonic development, in addition to their earlier expression in the inner cell mass of mammalian blastocysts. Functionally, Oct4 homologous proteins in Xenopus are required for neural induction and promote neuroectodermal gene expression (Cao et al., 2006; Snir et al., 2006). Sox2 in neural development has been well documented. In particular, the four reprogramming factors for generating iPSCs also induce NSCs/NPCs from fibroblasts (Lujan and Wernig, 2010). Likewise, neural crest cells share many key regulatory factors with blastula animal pole cells during Xenopus embryogenesis, and correspondingly, neural crest cells retain pluripotent differentiation potential as in blastula animal pole cells (Buitrago-Delgado et al., 2015). It is interesting that ESCs and primNSCs seem to be exchangeable. In addition to the demonstration of ESC-like pluripotent differentiation potential of NSCs/NPCs (Clarke et al., 2000; Tropepe et al., 2001; Xu et al., 2020), primNSCs can be derived from ESCs by putting ESCs into a defined serum-free medium, and vice versa, primNSCs can be reversed to the state of ESCs simply by putting primNSCs back into the ESC culture conditions (Tsang et al., 2013). Taking the evolutionary advantage of neural state into consideration, reprogramming of somatic cells into a pluripotent state should be interpreted as a process of restoring neural ground state in somatic cells, consequently leading to the gain of pluripotent differentiation potential and tumorigenicity, a process similar to that occurs during tumorigenesis. TGF $\beta$ signaling is required for neural inhibition during germ layer differentiation and for maintenance of ESC pluripotency (i.e., preventing ESCs from adopting a neural fate) (Ozair et al., 2013; Itoh et al., 2014; Meyers and Kessler, 2017). This means that TGF $\beta$ in ESCs represses the neural ground state on one hand and on the other, functions to prime the potential for non-neural differentiation (Sancho and Rodríguez, 2013; Gomes Fernandes et al., 2016). As differentiation continues, factors promoting differentiation of a particular cell type 
should inhibit further the neural ground state and meanwhile confer the property of the cell type. This relationship can be traced back to the transition from unicellularity to multicellularity during evolution. As a prime signaling for cell fate diversification, emergence of TGF $\beta$ pathway was accompanied with the start of multicellularity (Nichols et al., 2006). The pathway is not present in M. brevicollis (King et al., 2008; Srivastava et al., 2010), but present in A. queenslandica (Adamska et al., 2007; Srivastava et al., 2010). This multicellular organism represents the last common ancestor to living metazoans and develops with the least level of cell type diversification. Cells with pluripotent state are present in A. queenslandica, and pluripotency has a unicellular origin (Sogabe et al., 2019), which might be biased toward a neural state (Xu et al., 2020). Therefore, both our and previous studies by other groups support that neural stemness should represent the general stemness (Clarke et al., 2000; Xu et al., 2020)

The similarity in regulatory networks and cell properties between ESCs and primNSCs and the temporal order of cell differentiation during embryogenesis suggest that ESCs are most closely related with primNSCs. It is not surprising that most markers for ESCs or pluripotency are also markers for NSCs/NPCs or enriched in embryonic neural cells. With the progression of differentiation, stemness decreases gradually, until possibly a total loss in fully differentiated cells. There are somatic stem/progenitor cells in adult animals that are required for tissue regeneration and repair. These specific stem cells also display the properties like proliferation and self-renewal, but have restricted differentiation potential along a fixed lineage. They might represent an intermediary between the general stemness and a maturely differentiated state. They derive the properties of stemness from the general stemness, and meanwhile are conferred with the specific property of a lineage by lineage-specific regulatory factors. The association between general (or neural) stemness and the stemness of somatic tissues can be manifested by that many markers for NSCs/NPCs are also markers for somatic stem cells. For example, neural stemness markers BMI1, MSI1, SOX9 and CD133 can be used for labeling intestinal stem cells (Barker, 2013); the NSC marker NESTIN also identifies bone marrow mesenchymal stem cells (Méndez-Ferrer et al., 2010), hair follicle sheath progenitor cells ( $\mathrm{Li}$ et al., 2003), testicular stem Leydig cells (Jiang et al., 2014), and endothelial progenitor cells (Mokrý et al., 2004). These shared markers manifest similar stemness properties or regulate the properties via a similar mechanism between different types of stem/progenitor cells. Sox2, a marker for both NSCs and ESCs, regulates proliferation through conserved mechanisms and target genes in both NSCs and endodermal stem cells (Hagey et al., 2018). 


\section{Tumrogenesis and regeneration}

The capability of regeneration is inversely correlated with the evolutionary positions of animals, with higher regenerative capacity in lower animals and lower capacity in higher animals (Pesaresi et al., 2019). Moreover, animals at early developmental stage usually exhibit stronger regenerative capacity. There is also an inverse correlation between the propensity for regeneration and the capacity of tumorigenesis. It seems that animals with the ability of regeneration of complete limbs or head almost do not develop cancer, such as hydra (Kienle and Kiene, 2012). Dedifferentiation has been suggested as one of the major routes to regeneration (Jopling et al., 2011; Pesaresi et al., 2019). Dedifferentiation will cause the reversal of differentiated state into an undifferentiated state that is determined by neural ground state, and re-acquirement of differentiation potential. A prominent example is the dedifferentiation of myoblast cells in response to loss of a muscle differentiation factor Myod1 (Xu et al., 2020). Moreover, dedifferentiated fat cells display the potential of differentiation into multiple lineages, including neural lineage (Jumabay and Boström, 2015). Due to the increasing complexity of gene regulatory networks of cell differentiation during evolution, it can be postulated that cells in animals at lower evolutionary positions or at early developmental stages are more easily to dedifferentiate, and the dedifferentiated cells are more easily to re-differentiate under the control by a relatively simple regulatory network. By contrast, cells in higher animals or at adult stages are more difficult to dedifferentiate and re-differentiate because more sophisticated regulatory networks are involved. Consequently, higher animals have a low capacity of regeneration because of more complicated regulation of dedifferentiation and re-differentiation, which might have higher possibility of dysregulation. When dedifferentiate and re-differentiate are not regulated properly, cancer could occur because of the tumorigenicity of dedifferentiated cells.

\section{The current model and other models of tumorigenesis}

The analysis above indicates that tumorigenesis follows a general rule beneath the complicated genetic and phenotypic heterogeneity of tumors. Cells may experience different changes due to suffering from intracellular/extracellsular insults, including mutations, chromosomal instability, aneuploidy, microenviromental changes, gene misregulation, etc. Any single change is hard to explain the complexity of tumorigenesis. Whatever the insults are, the ultimate consequences should be the change in gene expression in cells. When tissue-specific genes or differentiation genes are accidentally downregulated/silenced or neural genes are upregulated/activated or both, the result will be the loss of original cell identity and gain of property of neural stemness and tumorigenicity. Gain of property of neural stemness means the capability of self-renewal and differentiation into different 
tissue/cell types, which contribute to tumor phenotypic heterogeneity. This is a default route that is pre-determined by evolution. The last common unicellular ancestors of metazoan had a neural biased state, the initial state for multicellularity. Emergence of novel genes and regulatory networks was required for inhibition of neural state to generate non-neural cells in metazoan. TGF $\beta$ signaling, which is critical for maintaining ESC pluripotency and neural inhibition, began to emerge in the basal species of metazoan such as A. queenslandica. It might be the earliest signal for diverting the neural state to a non-neural state, as it functions to prime the ESCs the potential to non-neural differentiation. Cells with pluripotency exist in A. queenslandica, which are most closely related with the unicellular relatives of metazoan (Sogabe et al, 2019). With the progression of metazoan evolution, regulation of cell differentiation becomes more complex, the property of neural stemness, the differential and tumorigenic potential in the cells is further decreased. Repression of differentiation signals will cause de-repression of neural ground state, leading to the gain of neural stemness, differentiation potential and tumorigenicity in either embryonic pluripotent cells (hence the 'neural default model') or somatic cells. This process of reverse evolution is a default route

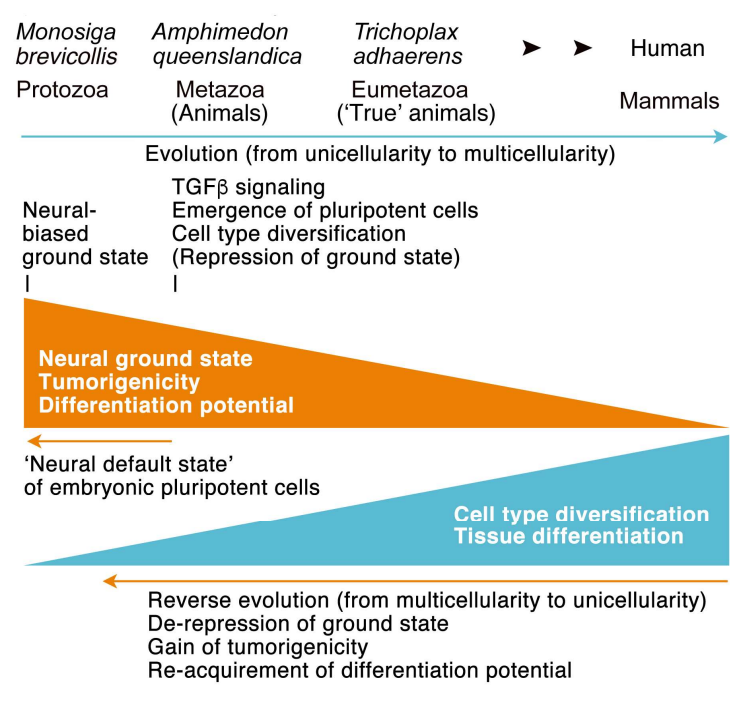

without the necessity of inducing signals, and is the most direct route hence for tumorigenesis. The proposed concept is illustrated in Fig. 3.

Fig. 3. A diagram depicting the relation between neural ground state, pluripotent differentiation potential and tumorigenesis from the view of evolution. See text for details.

The property of neural stemness is hopefully able to integrate different characteristics of tumorigenesis. As summarized in Table 2, NSCs/NPCs and TICs share regulatory networks, both exhibit neural stemness and differentiation potential; both are dependent on expression or activation of ancestral genes (the atavistic effect); both rely primarily on aerobic glycolytic metabolism; both can differentiate into various cells or tissues that are derived from all three germ layers, resembling severely disorganized or more severely degenerated form of embryonic development; both are enriched in longer genes with more splice variants that might provide more plastic scaffolds for cell differentiation, etc. This might be a key point to understand tumorigenesis and pluripotent differentiation potential. 


\section{Competing interests}

The author declares no potential competing interests.

\section{Author contributions}

Ying Cao conceived and wrote the review.

\section{References}

Abid H, Gnanajothy R. Osteoclast Giant Cell Tumor of Pancreas: A Case Report and Literature Review. Cureus. 2019 May 21;11(5):e4710.

Adamska M, Degnan SM, Green KM, Adamski M, Craigie A, Larroux C, Degnan BM. Wnt and TGF-beta expression in the sponge Amphimedon queenslandica and the origin of metazoan embryonic patterning. PLoS One. 2007 Oct 10;2(10):e1031.

Agnantis NT, Rosen PP. Mammary carcinoma with osteoclast-like giant cells. A study of eight cases with follow-up data. Am J Clin Pathol. 1979 Sep;72(3):383-9.

Al-Brahim N, Salama S. Malignant melanoma with osteoclast-like giant cells: an unusual host response: immunohistochemical and ultrastructural study of three cases and literature review. Am J Dermatopathol. 2005 Apr;27(2):126-9.

Alfarouk KO, Shayoub ME, Muddathir AK, Elhassan GO, Bashir AH. Evolution of Tumor Metabolism might Reflect Carcinogenesis as a Reverse Evolution process (Dismantling of Multicellularity). Cancers (Basel). 2011 Jul 22;3(3):3002-17.

Amariglio N, Hirshberg A, Scheithauer BW, Cohen Y, Loewenthal R, Trakhtenbrot L, Paz N, Koren-Michowitz M, Waldman D, Leider-Trejo L, Toren A, Constantini S, Rechavi G. Donor-derived brain tumor following neural stem cell transplantation in an ataxia telangiectasia patient. PLoS Med. 2009 Feb 17;6(2):e1000029.

Anzai H, Kazama S, Kiyomatsu T, Nishikawa T, Tanaka T, Tanaka J, Hata K, Kawai K, Yamaguchi H, Nozawa H, Kanazawa T, Ushiku T, Ishihara S, Sunami E, Fukayama M, Watanabe T. Alpha-fetoprotein-producing early rectal carcinoma: a rare case report and review. World J Surg Oncol. 2015 May 12;13:180.

Baralle FE, Giudice J. Alternative splicing as a regulator of development and tissue identity. Nat Rev Mol Cell Biol. 2017 Jul;18(7):437-451.

Barker N. Adult intestinal stem cells: critical drivers of epithelial homeostasis and regeneration. Nat Rev Mol Cell Biol. 2014 Jan;15(1):19-33.

Baserga R. Is cell size important? Cell Cycle. 2007;6(7):814-816.

Bauditz J, Rudolph B, Wermke W. Osteoclast like giant cell tumors of the pancreas and liver. World J Gastroenterol. 2006 Dec 28;12(48):7878-83.

Beck B, Blanpain C. Unravelling cancer stem cell potential. Nat Rev Cancer. 2013 Oct;13(10):727-38.

Beier D, Hau P, Proescholdt M, Lohmeier A, Wischhusen J, Oefner PJ, Aigner L, Brawanski A, Bogdahn U, Beier CP. CD133(+) and CD133(-) glioblastoma-derived cancer stem cells show differential growth characteristics and molecular profiles. Cancer Res. 2007 May 1;67(9):4010-5.

Ben-David U, Benvenisty N. The tumorigenicity of human embryonic and induced pluripotent stem cells. Nat Rev Cancer. 2011 Apr;11(4):268-77.

Bhat M, Robichaud N, Hulea L, Sonenberg N, Pelletier J, Topisirovic I. Targeting the translation machinery in cancer. Nat Rev Drug Discov. 2015 Apr;14(4):261-78.

Boumahdi S, Driessens G, Lapouge G, Rorive S, Nassar D, Le Mercier M, Delatte B, Caauwe A, Lenglez S, Nkusi E, Brohée S, Salmon I, Dubois C, del Marmol V, Fuks F, Beck B, Blanpain C. SOX2 controls tumour initiation and cancer stem-cell functions in squamous-cell carcinoma. Nature. 2014 Jul 10;511(7508):246-50. 
Bennett RL, Licht JD. Targeting Epigenetics in Cancer. Annu Rev Pharmacol Toxicol. 2018 Jan 6;58:187-207.

Buitrago-Delgado E, Nordin K, Rao A, Geary L, LaBonne C. NEURODEVELOPMENT. Shared regulatory programs suggest retention of blastula-stage potential in neural crest cells. Science. 2015 Jun 19;348(6241):1332-5.

Burrell RA, McGranahan N, Bartek J, Swanton C. The causes and consequences of genetic heterogeneity in cancer evolution. Nature. 2013 Sep 19;501(7467):338-45.

Bush SJ, Chen L, Tovar-Corona JM, Urrutia AO. Alternative splicing and the evolution of phenotypic novelty. Philos Trans R Soc Lond B Biol Sci. 2017 Feb 5;372(1713):20150474.

Bussey KJ, Cisneros LH, Lineweaver CH, Davies PCW. Ancestral gene regulatory networks drive cancer. Proc Natl Acad Sci U S A. 2017 Jun 13;114(24):6160-6162.

Bustelo XR, Dosil M. Ribosome biogenesis and cancer: basic and translational challenges. Curr Opin Genet Dev. 2018 Feb;48:22-29.

Cao Y. Tumorigenesis as a process of gradual loss of original cell identity and gain of properties of neural precursor/progenitor cells. Cell Biosci. 2017 Nov 7;7:61.

Cao Y, Siegel D, Knöchel W. Xenopus POU factors of subclass V inhibit activin/nodal signaling during gastrulation. Mech Dev. 2006 Aug;123(8):614-25.

Catez F, Dalla Venezia N, Marcel V, Zorbas C, Lafontaine DLJ, Diaz JJ. Ribosome biogenesis: An emerging druggable pathway for cancer therapeutics. Biochem Pharmacol. 2019 Jan;159:74-81.

Chau KF, Shannon ML, Fame RM, Fonseca E, Mullan H, Johnson MB, Sendamarai AK, Springel MW, Laurent B, Lehtinen MK. Downregulation of ribosome biogenesis during early forebrain development. Elife. 2018 May 10;7

Chen H, Lin F, Xing K, He X. The reverse evolution from multicellularity to unicellularity during carcinogenesis. Nat Commun. 2015 Mar 9;6:6367.

Chen Y, Zhang Y, Guo X. Proteasome dysregulation in human cancer: implications for clinical therapies. Cancer Metastasis Rev. 2017 Dec;36(4):703-716.

Cheng L, Hu W, Qiu B, Zhao J, Yu Y, Guan W, Wang M, Yang W, Pei G. Generation of neural progenitor cells by chemical cocktails and hypoxia. Cell Res. 2014 Jun;24(6):665-79.

Cheng L, Huang Z, Zhou W, Wu Q, Donnola S, Liu JK, Fang X, Sloan AE, Mao Y, Lathia JD, Min W, McLendon RE, Rich JN, Bao S. Glioblastoma stem cells generate vascular pericytes to support vessel function and tumor growth. Cell. 2013 Mar 28;153(1):139-52.

Cisneros L, Bussey KJ, Orr AJ, Miočević M, Lineweaver CH, Davies P. Ancient genes establish stress-induced mutation as a hallmark of cancer. PLoS One. 2017 Apr 25;12(4):e0176258.

Clarke DL, Johansson CB, Wilbertz J, Veress B, Nilsson E, Karlström H, Lendahl U, Frisén J. Generalized potential of adult neural stem cells. Science. 2000 Jun 2;288(5471):1660-3.

Clarke L, van der Kooy D. Low oxygen enhances primitive and definitive neural stem cell colony formation by inhibiting distinct cell death pathways. Stem Cells. 2009 Aug;27(8):1879-86.

Clevers H. The cancer stem cell: premises, promises and challenges. Nat Med. 2011 Mar;17(3):313-9.

Dagogo-Jack I, Shaw AT. Tumour heterogeneity and resistance to cancer therapies. Nat Rev Clin Oncol. 2018 Feb;15(2):81-94.

Dahm HH. Non-Small Cell Carcinoma of the Lung With Osteoclast-Like Giant Cells. Int J Surg Pathol. 2017 May;25(3):258-261.

Dekkers IA, Cleven A, Lamb HJ, Kroon HM. Primary Osteosarcoma of the Breast. Radiographics. 2019 May-Jun;39(3):626-629.

De Robertis EM. Spemann's organizer and self-regulation in amphibian embryos. Nat Rev Mol Cell Biol. 2006 Apr;7(4):296-302.

De Robertis EM, Kuroda H. Dorsal-ventral patterning and neural induction in Xenopus embryos. Annu Rev Cell Dev Biol. 2004;20:285-308.

Deng J, Zhang Y, Xie Y, Zhang L, Tang P. Cell Transplantation for Spinal Cord Injury: Tumorigenicity of Induced Pluripotent Stem Cell-Derived Neural Stem/Progenitor Cells. Stem Cells Int. 2018 Feb 4;2018:5653787. 
Dioscoridi L, Bisogni D, Freschi G. Hepatocellular carcinoma with osteoclast-like giant cells: report of the seventh case in the literature. Case Rep Surg. 2015;2015:836105.

Domazet-Lošo T, Brajković J, Tautz D. A phylostratigraphy approach to uncover the genomic history of major adaptations in metazoan lineages. Trends Genet. 2007;23(11):533-9.

Domazet-Lošo T, Tautz D. Phylostratigraphic tracking of cancer genes suggests a link to the emergence of multicellularity in metazoa. BMC Biol. 2010;8:66.

Drummond CJ, Hanna JA, Garcia MR, Devine DJ, Heyrana AJ, Finkelstein D, Rehg JE, Hatley ME. Hedgehog Pathway Drives Fusion-Negative Rhabdomyosarcoma Initiated From Non-myogenic Endothelial Progenitors. Cancer Cell. 2018 Jan 8;33(1):108-124.e5.

Dvinge H, Kim E, Abdel-Wahab O, Bradley RK. RNA splicing factors as oncoproteins and tumour suppressors. Nat Rev Cancer. 2016 Jul;16(7):413-30.

Fadare O, Gill SA. Solid neuroendocrine carcinoma of the breast with osteoclast-like giant cells. Breast J. 2009 Mar-Apr;15(2):205-6.

Fox RG, Lytle NK, Jaquish DV, Park FD, Ito T, Bajaj J, Koechlein CS, Zimdahl B, Yano M, Kopp J, Kritzik M, Sicklick J, Sander M, Grandgenett PM, Hollingsworth MA, Shibata S, Pizzo D, Valasek M, Sasik R, Scadeng M, Okano H, Kim Y, MacLeod AR, Lowy AM, Reya T. Image-based detection and targeting of therapy resistance in pancreatic adenocarcinoma. Nature. 2016 Jun 16;534(7607):407-411.

Friedmann-Morvinski D, Verma IM. Dedifferentiation and reprogramming: origins of cancer stem cells. EMBO Rep. 2014;15(3):244-53.

Gabel HW, Kinde B, Stroud H, Gilbert CS, Harmin DA, Kastan NR, Hemberg M, Ebert DH, Greenberg ME. Disruption of DNA-methylation-dependent long gene repression in Rett syndrome. Nature. 2015 Jun 4;522(7554):89-93.

Germain ND, Hartman NW, Cai C, Becker S, Naegele JR, Grabel LB. Teratocarcinoma formation in embryonic stem cell-derived neural progenitor hippocampal transplants. Cell Transplant. 2012;21(8):1603-11.

Gilbert SF, Barresi MJ. Early amphibian development. In Developmental Biology $\left(11^{\text {th }}\right.$ Edition, 2016), pp. 333-364. Massachusetts: Sinauer Associates, Inc.

Ginter PS, Petrova K, Hoda SA. The grossly "rusty" tumor of breast: invasive ductal carcinoma with osteoclast-like giant cells. Int J Surg Pathol. 2015 Feb;23(1):32-3.

Godsave SF, Slack JM. Clonal analysis of mesoderm induction in Xenopus laevis. Dev Biol. 1989 Aug; 134(2):486-90.

Goel G, Rao S, Khurana N. Malignant melanoma with osteoclast-like giant cells: A report of two cases. J Cancer Res Ther. 2011 Jul-Sep;7(3):336-8.

Gomes Fernandes M, Dries R, Roost MS, Semrau S, de Melo Bernardo A, Davis RP, Ramakrishnan R, Szuhai K, Maas E, Umans L, Abon Escalona V, Salvatori D, Deforce D, Van Criekinge W, Huylebroeck D, Mummery C, Zwijsen A, de Sousa Lopes SM. BMP-SMAD Signaling Regulates Lineage Priming, but Is Dispensable for Self-Renewal in Mouse Embryonic Stem Cells. Stem Cell Reports. 2016 Jan 12;6(1):85-94.

Gong W, Su Y, Liu A, Liu J, Sun D, Jiang T, Xiang J, Chi C, Sun P. Clinical characteristics and treatments of patients with alpha-fetoprotein producing gastric carcinoma. Neoplasma. 2018 Mar 14;65(3):326-330.

Grunz H, Tacke L. Neural differentiation of Xenopus laevis ectoderm takes place after disaggregation and delayed reaggregation without inducer. Cell Differ Dev. 1989;28(3):211-7. Hagey DW, Klum S, Kurtsdotter I, Zaouter C, Topcic D, Andersson O, Bergsland M, Muhr J. SOX2 regulates common and specific stem cell features in the CNS and endoderm derived organs. PLoS Genet. 2018 Feb 12;14(2):e1007224.

Hajdu SI. A Note From History: Landmarks in History of Cancer, Part 1. Cancer. 2011;117(5):1097-1102.

Hanselmann RG, Welter C. Origin of cancer: an information, energy, and matter disease. Front Cell Dev Biol. 2016;4:121.

Harland R. Neural induction. Curr Opin Genet Dev. 2000 Aug;10(4):357-62.

Hoorweg JJ, Loftus BM, Hilgers FJ. Osteoid and bone formation in a nasal mucosal melanoma and its metastasis. Histopathology. 1997 Nov;31(5):465-8.

Houang M, Castillo C, La Marca S, Combemale P, Wang Q, Paindavoine S, Pissaloux D, de 
la Fouchardiere A. An unusual case of desmoplastic melanoma containing an osteoclast-like giant cell-rich nodule. Am J Dermatopathol. 2015 Apr;37(4):299-304.

Ikeda T, Seki S, Maki M, Noguchi N, Kawamura T, Arii S, Igari T, Koike M, Hirokawa K. Hepatocellular carcinoma with osteoclast-like giant cells: possibility of osteoclastogenesis by hepatocyte-derived cells. Pathol Int. 2003 Jul;53(7):450-6.

Intlekofer AM, Finley LWS. Metabolic signatures of cancer cells and stem cells. Nat Metab. $2019 \mathrm{Feb} ; 1(2): 177-188$.

Itoh F, Watabe T, Miyazono K. Roles of TGF- $\beta$ family signals in the fate determination of pluripotent stem cells. Semin Cell Dev Biol. 2014 Aug;32:98-106.

Jiang MH, Cai B, Tuo Y, Wang J, Zang ZJ, Tu X, Gao Y, Su Z, Li W, Li G, Zhang M, Jiao J, Wan Z, Deng C, Lahn BT, Xiang AP. Characterization of Nestin-positive stem Leydig cells as a potential source for the treatment of testicular Leydig cell dysfunction. Cell Res. 2014 Dec;24(12):1466-85.

Jiménez-Heffernan JA, Adrados $\mathrm{M}$, Muñoz-Hernández $\mathrm{P}, \quad$ Fernández-Rico $\mathrm{P}$, Ballesteros-García AI, Fraga J. Cytologic Features of Malignant Melanoma with Osteoclast-Like Giant Cells. Acta Cytol. 2018;62(2):151-154.

Jopling C, Boue S, Izpisua Belmonte JC. Dedifferentiation, transdifferentiation and reprogramming: three routes to regeneration. Nat Rev Mol Cell Biol. 2011 Feb;12(2):79-89.

Jumabay M, Boström KI. Dedifferentiated fat cells: A cell source for regenerative medicine. World J Stem Cells. 2015 Nov 26;7(10):1202-14.

Kienle G, Kiene H. From Reductionism to Holism: Systems-oriented Approaches in Cancer Research. Glob Adv Health Med. 2012 Nov;1(5):68-77.

Kim DY, Rhee I, Paik J. Metabolic circuits in neural stem cells. Cell Mol Life Sci. 2014 Nov;71(21):4221-41.

Kim K, Higashi M, Fumino S, Tajiri T. Derivation of neural stem cells from human teratomas. Stem Cell Res. 2019 Dec;41:101633.

King N, Westbrook MJ, Young SL, Kuo A, Abedin M, Chapman J, Fairclough S, Hellsten U, Isogai Y, Letunic I, Marr M, Pincus D, Putnam N, Rokas A, Wright KJ, Zuzow R, Dirks W, Good M, Goodstein D, Lemons D, Li W, Lyons JB, Morris A, Nichols S, Richter DJ, Salamov A, Sequencing JG, Bork P, Lim WA, Manning G, Miller WT, McGinnis W, Shapiro H, Tjian R, Grigoriev IV, Rokhsar D. The genome of the choanoflagellate Monosiga brevicollis and the origin of metazoans. Nature. 2008 Feb 14;451(7180):783-8.

Knoepfler PS. Deconstructing stem cell tumorigenicity: a roadmap to safe regenerative medicine. Stem Cells. 2009 May;27(5):1050-6.

Kong L, Peng W, Liu J, Wang W, Gong P, Yu G, Li J. Squamous cell carcinoma of lung associated with osteoclast-like giant cells: report of a case. Int J Clin Exp Pathol. 2015 Sep 1;8(9):11823-5.

Kuwano H, Sonoda T, Hashimoto H, Enjoji M. Hepatocellular carcinoma with osteoclast-like giant cells. Cancer. 1984 Sep 1;54(5):837-42.

Lauvrak SU, Munthe E, Kresse SH, Stratford EW, Namløs HM, Meza-Zepeda LA, Myklebost O. Functional characterisation of osteosarcoma cell lines and identification of mRNAs and miRNAs associated with aggressive cancer phenotypes. $\mathrm{Br} \mathrm{J}$ Cancer. 2013 Oct 15;109(8):2228-36.

Lei A, Chen L, Zhang M, Yang X, Xu L, Cao N, Zhang Z and Cao Y. EZH2 Regulates Protein Stability via Recruiting USP7 to Mediate Neuronal Gene Expression in Cancer Cells. Front Genet. 2019 May 3;10:422.

Li L, Mignone J, Yang M, Matic M, Penman S, Enikolopov G, Hoffman RM. Nestin expression in hair follicle sheath progenitor cells. Proc Natl Acad Sci U S A. 2003 Aug 19;100(17):9958-61.

Li Z, Guo X, Huang H, Wang C, Yang F, Zhang Y, Wang J, Han L, Jin Z, Cai T, Xi R. A Switch in Tissue Stem Cell Identity Causes Neuroendocrine Tumors in Drosophila Gut. Cell Rep. 2020 Feb 11;30(6):1724-1734.e4.

Lindholm KE, Kalhor N, Moran CA. Osteoclast-like giant cell-rich carcinomas of the lung: a clinicopathological, immunohistochemical, and molecular study of 3 cases. Hum Pathol. 2019 Mar;85:168-173. 
Lujan E, Wernig M. The many roads to Rome: induction of neural precursor cells from fibroblasts. Curr Opin Genet Dev. 2012 Oct;22(5):517-22.

Malaguti M, Nistor PA, Blin G, Pegg A, Zhou X, Lowell S. Bone morphogenic protein signalling suppresses differentiation of pluripotent cells by maintaining expression of E-Cadherin. Elife. 2013 Dec 17;2:e1197.

Marusyk A, Almendro V, Polyak K. Intra-tumour heterogeneity: a looking glass for cancer? Nat Rev Cancer. 2012 Apr 19;12(5):323-34.

Massagué J. TGFbeta in Cancer. Cell. 2008 Jul 25;134(2):215-30.

Matsukuma S, Takeo H, Kato K, Sato K. Numerous osteoclast-like giant cells in metastases from lung adenocarcinoma, but absent from primary tumor. Thorac Cancer. 2014 $\mathrm{Jul} ; 5(4): 354-7$.

Matsumoto N, Pilz DT, Ledbetter DH. Genomic structure, chromosomal mapping, and expression pattern of human DCAMKL1 (KIAA0369), a homologue of DCX (XLIS). Genomics. 1999 Mar 1;56(2):179-83.

Mauffrey P, Tchitchek N, Barroca V, Bemelmans A, Firlej V, Allory Y, Roméo PH, Magnon C. Progenitors from the central nervous system drive neurogenesis in cancer. Nature. 2019 May;569(7758):672-678.

McGrail M, Batz L, Noack K, Pandey S, Huang Y, Gu X, Essner JJ. Expression of the zebrafish CD133/prominin1 genes in cellular proliferation zones in the embryonic central nervous system and sensory organs. Dev Dyn. 2010 Jun;239(6):1849-57.

McGranahan N, Swanton C. Biological and therapeutic impact of intratumor heterogeneity in cancer evolution. Cancer Cell. 2015 Jan 12;27(1):15-26.

Meacham CE, Morrison SJ. Tumour heterogeneity and cancer cell plasticity. Nature. 2013 Sep 19;501(7467):328-37.

Méndez-Ferrer S, Michurina TV, Ferraro F, Mazloom AR, Macarthur BD, Lira SA, Scadden DT, Ma'ayan A, Enikolopov GN, Frenette PS. Mesenchymal and haematopoietic stem cells form a unique bone marrow niche. Nature. 2010 Aug 12;466(7308):829-34.

Meyers EA, Kessler JA. TGF- $\beta$ Family Signaling in Neural and Neuronal Differentiation, Development, and Function. Cold Spring Harb Perspect Biol. 2017 Aug 1;9(8).

Mintz B, Illmensee K. Normal genetically mosaic mice produced from malignant teratocarcinoma cells. Proc Natl Acad Sci. 1975;72(9):3585-9.

Mizuguchi M, Qin J, Yamada M, Ikeda K, Takashima S. High expression of doublecortin and KIAA0369 protein in fetal brain suggests their specific role in neuronal migration. Am J Pathol. 1999 Nov; 155(5):1713-21.

Mohammad HP, Barbash O, Creasy CL. Targeting epigenetic modifications in cancer therapy: erasing the roadmap to cancer. Nat Med. 2019 Mar;25(3):403-418.

Mokrý J, Cízková D, Filip S, Ehrmann J, Osterreicher J, Kolár Z, English D. Nestin expression by newly formed human blood vessels. Stem Cells Dev. 2004 Dec;13(6):658-64.

Mullen AC, Wrana JL. TGF- $\beta$ Family Signaling in Embryonic and Somatic Stem-Cell Renewal and Differentiation. Cold Spring Harb Perspect Biol. 2017 Jul 5;9(7).

Muñoz-Sanjuán I, Brivanlou AH. Neural induction, the default model and embryonic stem cells. Nat Rev Neurosci. 2002;3(4):271-80.

Nakahashi H, Tsuneyoshi M, Ishida T, Minagawa S, Owaki Y, Momii S, Eimoto T. Undifferentiated carcinoma of the lung with osteoclast-like giant cells. Jpn J Surg. 1987 May;17(3):199-203.

Nakanishi Y, Seno H, Fukuoka A, Ueo T, Yamaga Y, Maruno T, Nakanishi N, Kanda K, Komekado H, Kawada M, Isomura A, Kawada K, Sakai Y, Yanagita M, Kageyama R, Kawaguchi Y, Taketo MM, Yonehara S, Chiba T. Dclk1 distinguishes between tumor and normal stem cells in the intestine. Nat Genet. 2013 Jan;45(1):98-103.

Nichols SA, Dirks W, Pearse JS, King N. Early evolution of animal cell signaling and adhesion genes. Proc Natl Acad Sci U S A. 2006 Aug 15;103(33):12451-6.

Nishimura K, Fukuda A, Hisatake K. Mechanisms of the Metabolic Shift during Somatic Cell Reprogramming. Int J Mol Sci. 2019 May 7;20(9):2254.

Njoumi N, Elalami FH, Attolou G, Saoud O, Elabsi M, Echarrab M, Elouannani M, Errougani A, Amraoui M, Chkoff MR. Undifferentiated pancreatic carcinoma with osteoclast-like giant 
cells: a case report. J Gastrointest Cancer. 2014 Dec;45 Suppl 1:96-8.

Ohashi R, Hayama A, Matsubara M, Watarai Y, Sakatani T, Naito Z, Shimizu A. Breast carcinoma with osteoclast-like giant cells: A cytological-pathological correlation with a literature review. Ann Diagn Pathol. 2018 Apr;33:1-5.

Ozair MZ, Kintner C, Brivanlou AH. Neural induction and early patterning in vertebrates. Wiley Interdiscip Rev Dev Biol. 2013 Jul;2(4):479-98.

Paduch R. Theories of cancer origin. Eur J Cancer Prev. 2015;24(1):57-67.

Papaioannou VE, McBurney MW, Gardner RL, Evans MJ. Fate of tetratocarcinoma cells injected into early mouse embryos. Nature. 1975;258:70-3.

Pelletier J, Thomas G, Volarević S. Ribosome biogenesis in cancer: new players and therapeutic avenues. Nat Rev Cancer. 2018 Jan;18(1):51-63.

Pesaresi M, Sebastian-Perez R, Cosma MP. Dedifferentiation, transdifferentiation and cell fusion: in vivo reprogramming strategies for regenerative medicine. FEBS J. 2019 Mar;286(6):1074-1093.

Peterson SE, Loring JF. Genomic instability in pluripotent stem cells: implications for clinical applications. J Biol Chem. 2014 Feb 21;289(8):4578-84.

Prasetyanti PR, Medema JP. Intra-tumor heterogeneity from a cancer stem cell perspective. Mol Cancer. 2017 Feb 16;16(1):41.

Quintanal-Villalonga Á, Chan JM, Yu HA, Pe'er D, Sawyers CL, Sen T, Rudin CM. Lineage plasticity in cancer: a shared pathway of therapeutic resistance. Nat Rev Clin Oncol. 2020 Jun;17(6):360-371.

Ra JC, Shin IS, Kim SH, Kang SK, Kang BC, Lee HY, Kim YJ, Jo JY, Yoon EJ, Choi HJ, Kwon E. Safety of intravenous infusion of human adipose tissue derived mesenchymal stem cells in animals and humans. Stem Cells Dev. 2011 Aug;20(8):1297 308.

Reavis HD, Chen HI, Drapkin R. Tumor Innervation: Cancer Has Some Nerve. Trends Cancer. 2020 Aug 14:S2405-8033(20)30213-2. doi: 10.1016/j.trecan.2020.07.005. Epub ahead of print. PMID: 32807693.

Ricci-Vitiani L, Lombardi DG, Pilozzi E, Biffoni M, Todaro M, Peschle C, De Maria R. Identification and expansion of human colon-cancer-initiating cells. Nature. 2007 Jan 4;445(7123):111-5.

Ricci-Vitiani L, Pallini R, Biffoni M, Todaro M, Invernici G, Cenci T, Maira G, Parati EA, Stassi G, Larocca LM, De Maria R. Tumour vascularization via endothelial differentiation of glioblastoma stem-like cells. Nature. 2010 Dec 9;468(7325):824-8.

Riggs JW, Barrilleaux BL, Varlakhanova N, Bush KM, Chan V, Knoepfler PS. Induced pluripotency and oncogenic transformation are related processes. Stem Cells Dev. 2013 Jan $1 ; 22(1): 37-50$.

Rosai J. Liver cell carcinoma with osteoclast-like giant cells: nonepitheliogenic giant cells in diverse malignancies. Hepatology. 1990 Oct;12(4 Pt 1):782-3.

Rousseau A, Bertolotti A. Regulation of proteasome assembly and activity in health and disease. Nat Rev Mol Cell Biol. 2018 Nov;19(11):697-712.

Sah SK, Li Y, Li Y. Undifferentiated carcinoma of the pancreas with osteoclast-like giant cells: a rare case report and review of the literature. Int J Clin Exp Pathol. 2015 Sep 1;8(9):11785-91.

Sahakyan AB, Balasubramanian S. Long genes and genes with multiple splice variants are enriched in pathways linked to cancer and other multigenic diseases. BMC Genomics. 2016 Mar 12;17:225.

Sancho M, Rodríguez TA. Ready, set, differentiate! Elife. 2013 Dec 17;2:e01839.

Sato SM, Sargent TD. Development of neural inducing capacity in dissociated Xenopus embryos. Dev Biol. 1989 Jul;134(1):263-6.

Scaffidi P, Misteli T. In vitro generation of human cells with cancer stem cell properties. Nat Cell Biol. 2011 Aug 21;13(9):1051-61.

Sebé-Pedrós A, Degnan BM, Ruiz-Trillo I. The origin of Metazoa: a unicellular perspective. Nat Rev Genet. 2017 Aug;18(8):498-512.

Seoane J, Gomis RR. TGF- $\beta$ Family Signaling in Tumor Suppression and Cancer Progression. Cold Spring Harb Perspect Biol. 2017 Dec 1;9(12). 
Serakinci N, Tulay P, Kalkan R. Role of Mesenchymal Stem Cells in Cancer Development and Their Use in Cancer Therapy. Adv Exp Med Biol. 2018;1083:45-62.

Shmelkov SV, Butler JM, Hooper AT, Hormigo A, Kushner J, Milde T, St Clair R, Baljevic M, White I, Jin DK, Chadburn A, Murphy AJ, Valenzuela DM, Gale NW, Thurston G, Yancopoulos GD, D'Angelica M, Kemeny N, Lyden D, Rafii S. CD133 expression is not restricted to stem cells, and both $\mathrm{CD} 133+$ and CD133- metastatic colon cancer cells initiate tumors. J Clin Invest. 2008 Jun;118(6):2111-20.

Smukler SR, Runciman SB, Xu S, van der Kooy D. Embryonic stem cells assume a primitive neural stem cell fate in the absence of extrinsic influences. J Cell Biol. 2006;172(1):79-90.

Snir M, Ofir R, Elias S, Frank D. Xenopus laevis POU91 protein, an Oct3/4 homologue, regulates competence transitions from mesoderm to neural cell fates. EMBO J. 2006 Aug 9;25(15):3664-74.

Soave CL, Guerin T, Liu J, Dou QP. Targeting the ubiquitin-proteasome system for cancer treatment: discovering novel inhibitors from nature and drug repurposing. Cancer Metastasis Rev. 2017 Dec;36(4):717-736.

Sogabe S, Hatleberg WL, Kocot KM, Say TE, Stoupin D, Roper KE, Fernandez-Valverde SL, Degnan SM, Degnan BM. Pluripotency and the origin of animal multicellularity. Nature. 2019 Jun;570(7762):519-522.

Solter, D. From teratocarcinomas to embryonic stem cells and beyond: a history of embryonic stem cell research. Nat Rev Genet 7, 319-327 (2006).

Srivastava M, Simakov O, Chapman J, Fahey B, Gauthier ME, Mitros T, Richards GS, Conaco C, Dacre M, Hellsten U, Larroux C, Putnam NH, Stanke M, Adamska M, Darling A, Degnan SM, Oakley TH, Plachetzki DC, Zhai Y, Adamski M, Calcino A, Cummins SF, Goodstein DM, Harris C, Jackson DJ, Leys SP, Shu S, Woodcroft BJ, Vervoort M, Kosik KS, Manning G, Degnan BM, Rokhsar DS. The Amphimedon queenslandica genome and the evolution of animal complexity. Nature. 2010 Aug 5;466(7307):720-6.

Stewart CJ, Mutch AF. Breast carcinoma with osteoclast-like giant cells. Cytopathology. 1991;2(4):215-9.

Sykova E, Forostyak S. Stem cells in regenerative medicine. Laser Ther. 2013;22(2):87-92.

Togawa Y, Tonouchi A, Chiku T, Sano W, Doki T, Yano K, Uno H, Muronoi T, Kaneoya K, Shinagawa T, Harigaya K, Toyoda A. A case report of undifferentiated carcinoma with osteoclast-like giant cells of the pancreas and literature review. Clin J Gastroenterol. 2010 Aug;3(4):195-203.

Trigos AS, Pearson RB, Papenfuss AT, Goode DL. Altered interactions between unicellular and multicellular genes drive hallmarks of transformation in a diverse range of solid tumors. Proc Natl Acad Sci U S A. 2017 Jun 13;114(24):6406-6411.

Trigos AS, Pearson RB, Papenfuss AT, Goode DL. How the evolution of multicellularity set the stage for cancer. Br J Cancer. 2018 Jan;118(2):145-152.

Tropepe V, Hitoshi S, Sirard C, Mak TW, Rossant J, van der Kooy D. Direct neural fate specification from embryonic stem cells: a primitive mammalian neural stem cell stage acquired through a default mechanism. Neuron. 2001 Apr;30(1):65-78.

Tsang WH, Wang B, Wong WK, Shi S, Chen X, He X, Gu S, Hu J, Wang C, Liu PC, Lu G, Chen X, Zhao H, Poon WS, Chan WY, Feng B. LIF-dependent primitive neural stem cells derived from mouse ES cells represent a reversible stage of neural commitment. Stem Cell Res. 2013 Nov;11(3):1091-102.

Turi Z, Lacey M, Mistrik M, Moudry P. Impaired ribosome biogenesis: mechanisms and relevance to cancer and aging. Aging (Albany NY). 2019 Apr 26;11(8):2512-2540.

Venkataramani V, Tanev DI, Strahle C, Studier-Fischer A, Fankhauser L, Kessler T, Körber C, Kardorff M, Ratliff M, Xie R, Horstmann H, Messer M, Paik SP, Knabbe J, Sahm F, Kurz FT, Acikgöz AA, Herrmannsdörfer F, Agarwal A, Bergles DE, Chalmers A, Miletic H, Turcan S, Mawrin C, Hänggi D, Liu HK, Wick W, Winkler F, Kuner T. Glutamatergic synaptic input to glioma cells drives brain tumour progression. Nature. 2019 Sep;573(7775):532-538.

Venkatesh HS, Morishita W, Geraghty AC, Silverbush D, Gillespie SM, Arzt M, Tam LT, Espenel C, Ponnuswami A, Ni L, Woo PJ, Taylor KR, Agarwal A, Regev A, Brang D, Vogel 
H, Hervey-Jumper S, Bergles DE, Suvà ML, Malenka RC, Monje M. Electrical and synaptic integration of glioma into neural circuits. Nature. 2019 Sep;573(7775):539-545.

Varela C, Denis JA, Polentes J, Feyeux M, Aubert S, Champon B, Piétu G, Peschanski M, Lefort N. Recurrent genomic instability of chromosome 1q in neural derivatives of human embryonic stem cells. J Clin Invest. 2012 Feb;122(2):569-74.

Vermeulen L, Todaro M, de Sousa Mello F, Sprick MR, Kemper K, Perez Alea M, Richel DJ, Stassi G, Medema JP. Single-cell cloning of colon cancer stem cells reveals a multi-lineage differentiation capacity. Proc Natl Acad Sci U S A. 2008 Sep 9;105(36):13427-32.

Wang BD, Lee NH. Aberrant RNA Splicing in Cancer and Drug Resistance. Cancers (Basel). 2018 Nov 20;10(11):458.

Wang R, Chadalavada K, Wilshire J, Kowalik U, Hovinga KE, Geber A, Fligelman B, Leversha M, Brennan C, Tabar V. Glioblastoma stem-like cells give rise to tumour endothelium. Nature. 2010 Dec 9;468(7325):829-33.

Xu L, Zhang M, L Shi, Yang X, Chen L, Cao N, Lei A, Cao Y. Neural stemness contributes to cell tumorigenicity. Research Square. 2020 Aug 3; DOI: 10.21203/rs.3.rs-49965/v1.

Xu Y, Zhang M, Li W, Zhu X, Bao X, Qin B, Hutchins AP, Esteban MA. Transcriptional Control of Somatic Cell Reprogramming. Trends Cell Biol. 2016 Apr;26(4):272-288.

Yachida S, Fukushima N, Nakanishi Y, Akasu T, Kitamura H, Sakamoto M, Shimoda T. Alpha-fetoprotein-producing carcinoma of the colon: report of a case and review of the literature. Dis Colon Rectum. 2003 Jun;46(6):826-31.

Ying QL, Stavridis M, Griffiths D, Li M, Smith A. Conversion of embryonic stem cells into neuroectodermal precursors in adherent monoculture. Nat Biotechnol. 2003a Feb;21(2):183-6.

Ying QL, Nichols J, Chambers I, Smith A. BMP induction of Id proteins suppresses differentiation and sustains embryonic stem cell self-renewal in collaboration with STAT3. Cell. 2003b Oct 31;115(3):281-92.

Yona AH, Manor YS, Herbst RH, Romano GH, Mitchell A, Kupiec M, Pilpel Y, Dahan O. Chromosomal duplication is a transient evolutionary solution to stress. Proc Natl Acad Sci U S A. 2012 Dec 18;109(51):21010-5.

Yong KW, Choi JR, Dolbashid AS, Wan Safwani WKZ. Biosafety and bioefficacy assessment of human mesenchymal stem cells: what do we know so far? Regen Med. 2018 Mar;13(2):219-232.

Zeng Q, Michael IP, Zhang P, Saghafinia S, Knott G, Jiao W, McCabe BD, Galván JA, Robinson HPC, Zlobec I, Ciriello G, Hanahan D. Synaptic proximity enables NMDAR signalling to promote brain metastasis. Nature. 2019 Sep;573(7775):526-531.

Zhang Z, Lei A, Xu L, Chen L, Chen Y, Zhang X, Gao Y, Yang X, Zhang M, Cao Y. Similarity in gene-regulatory networks suggests that cancer cells share characteristics of embryonic neural cells. J Biol Chem. 2017 Aug 4;292(31):12842-12859.

Zheng X, Boyer L, Jin M, Mertens J, Kim Y, Ma L, Ma L, Hamm M, Gage FH, Hunter T. Metabolic reprogramming during neuronal differentiation from aerobic glycolysis to neuronal oxidative phosphorylation. Elife. 2016 Jun 10;5:e13374.

Zylka MJ, Simon JM, Philpot BD. Gene length matters in neurons. Neuron. 2015 Apr 22;86(2):353-5. 